\title{
A STUDY OF HISTO PATHOLOGICAL CHANGES OF PLACENTA IN SEVERE ANAEMIA
}

Adil S. A. K. Nausheen Rumana

1. Assistant Professor, Department of Pathology, Mysore Medical College and Research Institute, Mysore.

2. Associate Professor, Department of Physiology, Mysore Medical College and Research Institute, Mysore.

\section{CORRESPONDING AUTHOR}

Dr. S. A. K. Adil, Assistant Professor,

\#259, $5^{\text {th }}$ Main, Bannimantap, 'C' Layout,

Mysore -570015 .

E-mail: saka291@yahoo.co.in,

Ph: 00919019691259.

ABSTRACT: BACKGROUND: Maternal disorders will influence the placenta, as it forms a functional unit between the mother and the fetus. Severe anaemia has many effects on important organs. In pregnancy it is associated with late abortions, prematurity, low birth weight and stillbirths $1,2,3,4,5$. Microscopic abnormalities of placenta may provide crucial information. Hence, the present study was under taken to analyse, the spectrum of histopathological changes in placenta, in severe anaemia during pregnancy. METHODS: One hundred and twelve placentas were studied of which, 56 belonged to mothers with severe anaemia and 56 belonged to mothers with normal haemoglobin. Histological sections made from placental tissue bits, taken from the central placenta were studied. Four hundred villi were counted, and different histopathological features were quantified. The mean number of villi showing syncytial knots, vasculo- syncytial membrane, fibrinoid necrosis and villous stromal fibrosis was determined. The comparison of the means was done using students unpaired ' $t$ ' test. Test of proportion was applied wherever necessary. RESULTS: Significant microscopic changes were observed in placentae of anaemia group as compared to controls. Villi in placentas from mothers with severe anaemia showed excessive syncytial knots $(\mathrm{p}<0.001)$, increased fibrinoid necrosis of the villi $(p<0.001)$, increased villous stromal fibrosis $(\mathrm{p}<0.001)$ compared to villi of placentas from mothers with normal haemoglobin. The difference of proportion of villi showing vasculo-syncytial membranes between the two group was statistically not significant ( $p>0.05$ ).

CONCLUSION: Severe anaemia in pregnancy alters the placental morphology and adequate treatment of anaemia may therefore be critical to normal placental function.

KEY WORDS: Placenta, villi, severe anaemia.

INTRODUCTION: The fetus, placenta, and the mother constitute the triad of contributors to pregnancy outcome. Examination of the placenta in cases of poor pregnancy outcome and maternal disorders, provides, vital information to both obstetricians and neonatologist. Severe anaemia is a potentially hazardous hematological disorder that may occur in pregnancy. It affects many important organs of the body. ${ }^{6}$ There is paucity of literature on histopathology of placenta in severe anaemia during pregnancy. Few previous studies on histopathological changes in placenta have shown varying results. These conflicting results may be due to the fact that the design of these studies varied. Hence, the present study was under taken to analyse the spectrum of histopathological changes in placenta in severe anaemia during pregnancy. 
MATERIAL AND METHODS: This present prospective study on placentae obtained from mothers delivering at district hospital, Belgaum, from April 2004 to March 2005, was undertaken in the Department of Pathology, Jawaharlal Nehru Medical College, Belgaum. Written consent was taken from the mothers after explaining the study details and mother's proforma was maintained. A total of 112 placentae were studied, of which, 56(50\%) placentae were from mothers with severe anaemia $(\mathrm{Hb}<7 \mathrm{~g} / \mathrm{dl})$ who formed the anaemia group and $56(50 \%)$ placentae were from normal term mothers $(\mathrm{Hb} \geq 11 \mathrm{~g} / \mathrm{dl})$ who formed the control group.

\section{INCLUSION CRITERIA:}

\section{CONTROL GROUP:}

1) Singleton uncomplicated term pregnancy 2) Baby weight $>2.5 \mathrm{Kg} 3$ )Gestational period $>37$ - 41weeks 4)Blood pressure < $140 / 90 \mathrm{~mm}$ of $\mathrm{Hg}$ throughout pregnancy 5) Haemoglobin value is $11 \mathrm{~g} / \mathrm{dl}$ and above.

\section{ANAEMIA GROUP:}

1) Singleton pregnancy 2) Gestational period $>37-41$ weeks 3) Blood pressure < $140 / 90 \mathrm{~mm}$ of $\mathrm{Hg}$ throughout pregnancy 4) Haemoglobin value is $<7 \mathrm{~g} / \mathrm{dl}$.

\section{EXCLUSION CRITERIA:}

1. Associated obstetric complications of pregnancy.

2. Associated medical disorders of pregnancy.

3. Twin pregnancies.

Haemoglobin estimation was done by cyanmethaemoglobin method. The severity of anaemia among the mothers was judged by the criteria suggested by WHO. 7,8 .

Gross lesions of the placenta were examined and the placenta was kept for fixation in $10 \%$ formal saline for 24-48 hours. After fixation, the placenta was cut into vertical strips (bread loaf manner) of $0.5 \mathrm{cms}$ thickness each. Four slices were taken from the central area of each placenta and sections were cut from the central zone of each slice as recommended by Fox H. ${ }^{9}$

The tissue bits were then processed through series of dehydration steps and embedded in wax blocks. Tissue sections of $5 \mu \mathrm{m}$ thickness were cut from each block and stained by conventional haematoxylin and eosin stain and according to findings, special staining techniques like P.A.S (Periodic Acid Schiff), Van Geison, Von Kossa and Masson's trichrome were employed. The different histological findings were observed against the background of normal standards of histology of placenta as described by Fox H. ${ }^{9}$

Different histological features were quantified. In each placenta four hundred villi were counted and the incidence of various histological features was determined, according to the method proposed by Fox H.9 ${ }^{9}$ The mean number of villi showing syncytial knots, vasculosyncytial membrane, fibrinoid necrosis and villous stromal fibrosis was then determined. The comparison of the means was done using students unpaired ' $t$ ' test. Test of proportion was applied wherever necessary. 
RESULTS: Syncytial knots were present on $>30$ percent of the villi in 34/56(60.71\%) placentae of the anaemia group and 11/56(19.64\%) placentae of the control group. The difference of proportion of placentae showing high villous syncytial knot counts ( $>30 \%$ of the villi) between the two groups was statistically significant ( $\mathrm{p}<0.001$ ) (Table1).

This shows that higher proportion of placentae in anaemia group show syncytial knots on more number of villi.

Vasculo-syncytial membranes were present in $>20$ percent of the villi in $7 / 56(12.5 \%)$ placentae of the control group and 2/56(3.57\%) placentae of the anaemia group. The difference of proportion of placentae showing vasculo-syncytial membranes in $>20$ percent of the villi between the two group was statistically not significant $(p>0.05)$ and none of the placentae in both the groups showed deficiency of membranes (i.e. $<5 \%$ of the villi) or had high vasculosyncytial membrane count (i.e. $>30 \%$ of the villi) (Table2).

Fibrinoid necrosis was seen in $>3$ percent of the villi in $6 / 56(10.71 \%)$ placentae of the control group and 30/56(53.57\%) placentae of the anaemia group. The difference of proportion of placentae showing fibrinoid necrosis in $>3$ percent of the villi between the two groups was statistically very significant $(\mathrm{p}<0.001)$.This shows that fibrinoid necrosis is commonly seen in placentae of anaemia cases (Table 3).

Increase in villous stromal fibrosis was seen in 4/56 (7.14\%) placentae of the control group and 24/56(42.85\%) placentae of the anaemia group. The difference of proportion of placentae showing increase in stromal fibrosis in $>3$ percent of the villi between the two groups was statistically very significant $(\mathrm{p}<0.001)$. This shows that increase in villous stromal fibrosis is commonly seen in placentae of anaemia cases (Table 4).

The mean number of villi showing syncytial knots was19.7 \pm 7.55 in control group and that in anaemia group was31.01 \pm 3.29 , the mean number of villi with vasculo-syncytial membrane in control group was15.63 \pm 4.45 and that in anaemia group was $12.05 \pm 4.83$, the mean number of villi showing fibrinoid necrosis was1.64 \pm 1.43 in control group and $3.26 \pm 2.29$ in anaemia group, the mean number of villi showing increase in stromal fibrosis was $1.45 \pm 1.39$ in control group and that in anemia group was 4.08 \pm 2.07 .

The difference in the mean number of villi showing syncytial knots $(\mathrm{p}<0.001)$, vasculosyncytial membrane $(\mathrm{p}<0.01)$, fibrinoid necrosis $(\mathrm{p}<0.01)$ and increase stromal fibrosis $(p<0.001)$ between the two groups was statistically significant between the two groups. (Table 5).

DISCUSSION: In severe anaemia, there is decrease in oxygen carrying capacity of the blood which affects tissue perfusion and therefore, vital organs like heart, kidney, liver, lungs and brain would show signs of reduced work function. The growth and survival of the fetus in utero is directly related to formation, development and maturation of the placenta. Severe anaemia during pregnancy has a significant impact on mother and fetus. It is a cause of pre-placental hypoxia, which may give origin to fetal hypoxia resulting in serious problems for the developing fetus.

Histopathological examinations of the placenta can reveal changes which may be associated with maternal disorders and also result in feto-maternal complications. Placental studies are quantitative rather than qualitative as some changes take place in placenta before it separates from the uterus. The changes are considered pathological when the extent of involvement is greater than normal ${ }^{9}$. The present study was carried out to compare various parameters of placental histology and their significance. 
Syncytial knots are composed of aggregates of small, closely packed densely staining nuclei protruding from the villous surface into the intervillous space. In the literature, it is hypothesized that villous hypovascularity leads to formation of syncytial knots, indicating sequestration of aged nuclei is being accelerated or augmented so as to use optimally the amount of trophoblast available for transfer purpose. ${ }^{9}$ Increased syncytial knots in placentae in anaemia suggested that an attempt was being made to form new villi so as to increase an effective surface area for exchange. ${ }^{10}$

Syncytial knots in more than $30 \%$ of the villi are considered excessive. ${ }^{11}$ In the present study, high villous syncytial count (i.e. over $30 \%$ of the villi showing syncytial knots) were seen in 34/56 placentae of anaemia group as compared to 11/56 placentae of control group. A study reported low incidence of excessive syncytial knots in anaemia group. ${ }^{12}$

But, other studies have reported high villous syncytial counts.13, 14. Few studies did not find any difference in the incidence of syncytial knots in anaemia and control group. ${ }^{15,16 .}$

Vasculo-syncytial membranes are focally differentiated areas of syncytiotrophoblast which are specifically concerned with materno-fetal transfer. It consists of attenuated anuclear syncytiotrophoblast stretched over, and in close apposition to, a sinusoidally dilated vessel. ${ }^{9}$ Vasculo-syncytial membrane counts measure the approximation of the villi to optimal maturity and hence give a good indication of the ability of the placenta to supply oxygen to the foetus. ${ }^{9}$

Placentae in which between 6 and 30 percent of the villi show Vasculo-syncytial membranes are said to have a normal count. ${ }^{17}$. In the present study, all the placentae in both groups had Vasculo- syncytial membrane count within the normal range. None of the placentae showed deficiency of membranes $(<5 \%$ of the villi) nor had high Vasculo-syncytial membrane count ( $>30 \%$ of the villi). The mean number of villi with vasculo-syncytial membrane with per 100 villi was 12.08 in anaemia group compared to 15.62 in control group the difference between the two groups was statistically significant $(\mathrm{p}<0.01)$ (table 5)But there was no deficiency of the membranes in the anaemia group and the control group. It may therefore just suggest placental maturity in both the groups. In contrast, an earlier study documented increase in the vasculo-syncytial membrane counts in anaemia group.10

Fibrinoid necrosis is seen as a nodular mass of homogeneous acidophilic material in the villi. Placentae in which fibrinoid necrosis involving upto three percent of placental villi is considered as normal. ${ }^{18}$

Fibrinoid necrosis may be a degenerative change in villous trophoblast. ${ }^{18}$ Recent literature suggests it to be an immunological reaction within the trophoblastic tissue. ${ }^{9}$

In the present study, 30/56 (53.57\%) placentae of anaemia group showed more villi with fibrinoid necrosis count as compared to $6 / 56(10.71 \%)$ placentae of control group. The mean number of villi showing fibrinoid necrosis per 100 villi was 3.26 in anaemia group and 1.64 in the control group. The difference between the two groups was statistically significant $(\mathrm{p}<0.001)$ this finding was in conformity with earlier studies.13, 14, 16. In contrast, a study has reported decreased incidence of villi with fibrinoid necrosis, in severe anaemia subgroup. ${ }^{12}$

In term placenta normally $\leq 3$ percent of villi may show increase in stromal fibrosis. ${ }^{19}$ Increase villous stromal fibrosis seen in the anaemic placentae may be the result of relative hypoxia in the peripheral part of the placental lobule.

In the present study, 24/56 (42.85\%) placentae of anaemia group revealed increase in the incidence of villi with stromal fibrosis as compared to 4/56 (7.14\%) placentae of control group. The difference between the two groups was statistically very significant $(\mathrm{p}<.001)$. The mean number of fibrotic villi per 100 villi was 4.08 in anaemia group and 1.44 in the control 
group. ${ }^{10}$ Earlier studies have also reported increase in villous stromal fibrosis in the anaemia cases. ${ }^{12,13,15,16 .}$

\section{CONCLUSION:}

The present study which was undertaken to evaluate the possible histopathological changes and quantitate them showed significant microscopic changes in placentae of anaemia group as compared to controls.

1. Placenta in severe anaemia showed excessive syncytial knots, increased fibrinoid necrosis of the villi, increased villous stromal fibrosis.

2. Quantitative determination of placental changes is essential in study of placenta as normal pregnancies can also show significant placental changes.

3. Severe anaemia in pregnancy alters the placental morphology and adequate treatment of anaemia may therefore be critical to normal placental function.

ACKNOWLEDGEMENT: Dr. P. V. Patil mD, PhD, DHA, Fic Path. Professor and H.O.D, Department of Pathology, J. N. Medical College, Belgaum for guiding me in the study.

\section{REFERENCES:}

1. Klebanoff MA, Shrono PH, Selby JU, Trachtenberg AI, Gaubard BI. Anemia and spontaneous preterm birth. Am J Obstet Gynaecol 1991; 164: 59-63.

2. Liebermani E, Ryan KJ, Monson RR. Association of maternal hematocrit with premature labour. Am J Obstet. Gynaecol. 1988; 159:107.

3. Murphy JE, O' Riordan J, Newcombe RG, Coles EC. Relation of haemoglobin levels in first and second trimester to outcome of pregnancy. Lancet 1986; 1:992.

4. Agarwal KN. Functional consequences of nutritional anaemia. Proc Nutr Soc Ind. 1991; 37: 127-132.

5. Pandya P, Hazra MN.Fetomaternal outcome in patients of severe anaemia in pregnancy.J Obstet Gynaec India1993;43(1):5-10

6. Firkin F, Chesterman C, Penington D, Rush B.The red cell and anaemia.In:de Gruchy's clinical haematology in medical practice. $5^{\text {th }}$ edn.Calcutta: Oxford university press; 1990.26-27.

7. World Health Organization. Prevention and management of severe anaemia in pregnancy. Geneva WHO; 1993.

8. World Health Organization. Preventing and controlling Iron deficiency anaemia through primary health care. WHO publications 1989.2

9. Fox H. Pathology of placenta. $2^{\text {nd }}$ edn Philadelphia: W.B. Saunders Co.Ltd; 1997.

10. Dhall U. Histological changes in placenta in anaemia: A Quantitative study. J Anat Soc India 1994; 43(1):21-26

11. Fox H. The significance of villous syncytial knots in the human placenta. J Obstet Gynaec Brit Cwlth. 1965; 72:347-355.

12. Rangnekar AG, Darbari R. Placental changes in pregnancy anaemia. Study of one hundred cases. J Obstet Gynaecol India 1993; 43; 473-478.

13. Sabharwal BD, Malhotra V, Sofat R, Duggal A. Histopathology of placenta in pregnancy anaemia. J Obstet Gynaecol India 1987; 37:773-776. 
14. Gyatri V, Jain S,Kalra R,Karla VB,Sareen PM,Lodha KS et al.Histopathology of placenta in pregnancy anaemia.J Obstet Gynaecol India 1983;33:187-189.

15. Agboola A. Placental changes in patients with a low haemotocrit. The British Journal of Obstetrics and Gynaecology. 1975; 82:225-227.

16. Khanna S, Chand S, Singla PN, Agarwal KN. Morphological study of placenta in pregnancy anaemia. J Obstet Gynaecol India 1979;22:7-12.

17. Fox. H. The incidence and significance of vasculo-syncytial membranes in the human placenta. J Obstet Gynaec Brit Cwlth. 1967;74:28-33.

18. Fox H. Fibrinoid necrosis of placental villi. J Obstet Gynaec Brit Cwlth. 1968; 75:448452.

19. Fox H. Fibrosis of placental villi. J Pathology and bacteriology. 1968; 95:573-579

Table 1: Incidence of increased syncytial knots:

\begin{tabular}{|l|l|l|l|l|l|}
\hline \multirow{2}{*}{ Group } & $\begin{array}{l}\text { Percentage of } \\
\text { villi with } \\
\text { syncytial knots }\end{array}$ & $\begin{array}{l}\text { Number of } \\
\text { placentae }\end{array}$ & Percentage & z value & p value \\
\hline \multirow{2}{*}{ Control } & $\mathbf{3 0 \%}$ & $\mathbf{4 5}$ & $\mathbf{8 0 . 3 5}$ & \multirow{2}{*}{4.4330} & \multirow{2}{*0.001}{} \\
\cline { 2 - 6 } & $\mathbf{3 0 \%}$ & $\mathbf{1 1}$ & $\mathbf{1 9 . 6 4}$ & $\mathbf{3 9 . 2 8}$ & \\
\hline \multirow{2}{*}{ Anemia } & $\mathbf{3 0 \%}$ & $\mathbf{2 2}$ & $\mathbf{6 0 . 7 1}$ & & \\
\cline { 2 - 5 } & $\mathbf{3 0 \%}$ & $\mathbf{3 4}$ & & & \\
\hline
\end{tabular}

Table 2: Incidence of Vasculo-syncytial membranes:

\begin{tabular}{|l|l|l|l|l|l|}
\hline Group & $\begin{array}{l}\text { Percentage of } \\
\text { villi with } \\
\text { vasculo } \\
\text { syncytial } \\
\text { membrane }\end{array}$ & $\begin{array}{l}\text { Number of } \\
\text { placentae }\end{array}$ & Percentage & z value & p value \\
\hline Control & $\leq \mathbf{2 0}$ & $\mathbf{4 9}$ & $\mathbf{8 7 . 5}$ & \multirow{2}{*}{$\mathbf{1 . 7 3 8 0}$} & $\mathbf{2 0 . 0 5}$ \\
\hline & $\mathbf{2 0}$ & $\mathbf{7}$ & $\mathbf{1 2 . 5}$ & $\mathbf{9 6 . 4 2}$ & \\
\hline Anaemia & $\leq \mathbf{2 0}$ & $\mathbf{5 4}$ & $\mathbf{3 . 5 7}$ & \\
\hline & $>\mathbf{2 0}$ & $\mathbf{2}$ & & & \\
\hline
\end{tabular}


Table 3: Incidence of increased fibrinoid necrosis (Intravillous fibrinoid):

\begin{tabular}{|l|l|l|l|l|l|}
\hline Group & $\begin{array}{l}\text { Percentage of } \\
\text { villi showing } \\
\text { fibrinoid } \\
\text { necroses }\end{array}$ & $\begin{array}{l}\text { Number of } \\
\text { placentae }\end{array}$ & Percentage & z value & p value \\
\hline Control & $\leq \mathbf{3}$ & $\mathbf{5 0}$ & $\mathbf{8 9 . 2 8}$ & \multirow{2}{*}{ 4.8558 } & \multirow{2}{*0.001}{} \\
\hline & $>\mathbf{3}$ & $\mathbf{0 6}$ & $\mathbf{1 0 . 7 1}$ & \\
\hline Anaemia & $\leq \mathbf{3}$ & $\mathbf{2 6}$ & $\mathbf{4 6 . 4 2}$ & \\
\hline & $>\mathbf{3}$ & $\mathbf{3 0}$ & $\mathbf{5 3 . 5 7}$ & \\
\hline
\end{tabular}

Table 4: Incidence of increased fibrotic villi (Increased villous stromal fibrosis):

\begin{tabular}{|l|l|l|l|l|l|}
\hline Groups & $\begin{array}{l}\text { Percentage of } \\
\text { fibrotic villi }\end{array}$ & $\begin{array}{l}\text { Number of } \\
\text { placentae }\end{array}$ & Percentage & z value & P value \\
\hline Control & $\leq \mathbf{3}$ & $\mathbf{5 2}$ & $\mathbf{9 2 . 8 5}$ & & \\
\hline & $>\mathbf{3}$ & $\mathbf{4}$ & $\mathbf{7 . 1 4}$ & $\mathbf{4 . 3 6 4 4}$ & $<\mathbf{0 . 0 0 1}$ \\
\hline Anaemia & $\leq \mathbf{3}$ & $\mathbf{3 2}$ & $\mathbf{5 7 . 1 4}$ & & \\
\hline & $>\mathbf{3}$ & $\mathbf{2 4}$ & $\mathbf{4 2 . 8 5}$ & & \\
\hline
\end{tabular}

Table 5: Mean number of histological parameters (per 100 villi):

\begin{tabular}{|l|l|l|l|}
\hline Histological parameter & $\begin{array}{l}\text { Control group } \\
(\mathrm{n}=56)\end{array}$ & $\begin{array}{l}\text { Anaemia group } \\
(\mathrm{n}=56)\end{array}$ & p value \\
\hline Syncytial knots & $\mathbf{1 9 . 7} \pm \mathbf{7 . 5 5}$ & $\mathbf{3 1 . 0 1} \pm \mathbf{3 . 2 9}$ & $<\mathbf{0 . 0 0 1}$ \\
\hline $\begin{array}{l}\text { Vasculo-syncytial } \\
\text { membranes }\end{array}$ & $\mathbf{1 5 . 6 3} \pm \mathbf{4 . 4 5}$ & $\mathbf{1 2 . 0 5} \pm \mathbf{4 . 8 3}$ & $>\mathbf{0 . 0 1}$ \\
\hline Fibrinoid necrosis & $\mathbf{1 . 6 4} \pm \mathbf{1 . 4 3}$ & $\mathbf{3 . 2 6} \pm \mathbf{2 . 2 9}$ & $<\mathbf{0 . 0 1}$ \\
\hline Fibrotic villi & $\mathbf{1 . 4 5} \pm \mathbf{1 . 3 9}$ & $\mathbf{4 . 0 8} \pm \mathbf{2 . 0 7}$ & $<\mathbf{0 . 0 0 1}$ \\
\hline
\end{tabular}




\section{ORIGINAL ARTICLE}

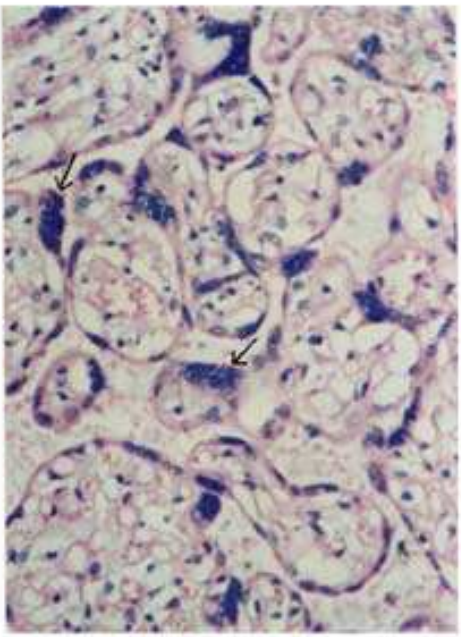

Fig 1-Villi showing excessive Syncytial knots (H \&E, X 10)

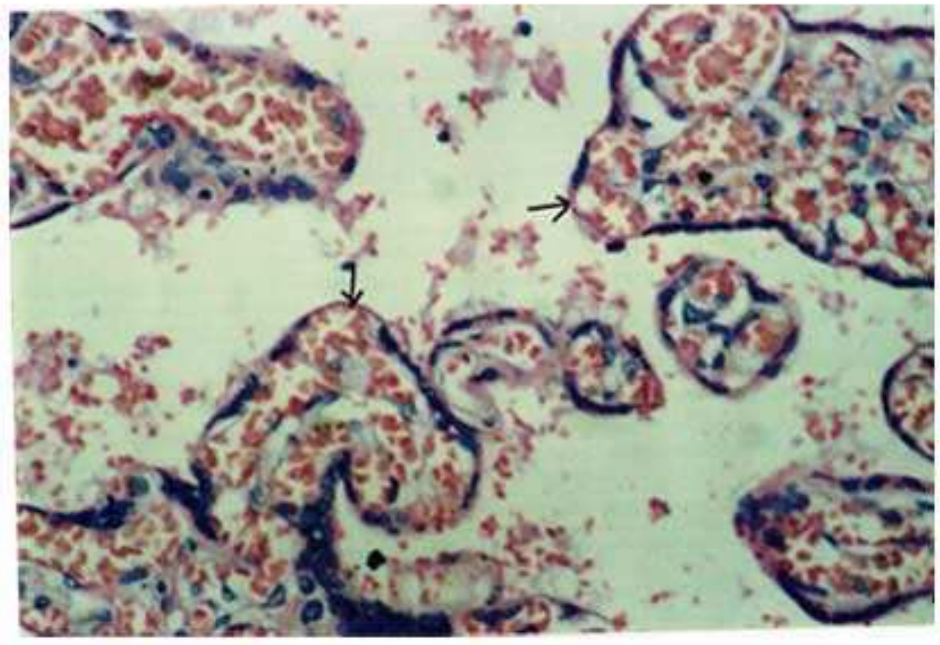

Fig 2-Villi showing Vasculo-syncytial membranes (H \& E, X40)

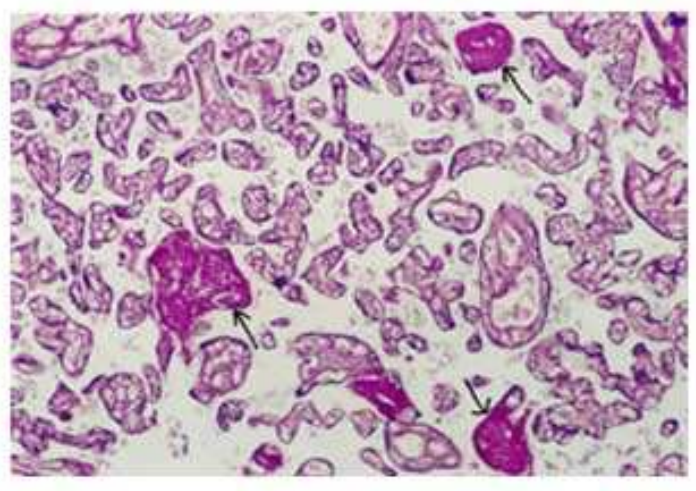

Fig 3-Villi showing Fibrinoid necrosis (Intravillous fibrinoid) (P.A.S, X40)

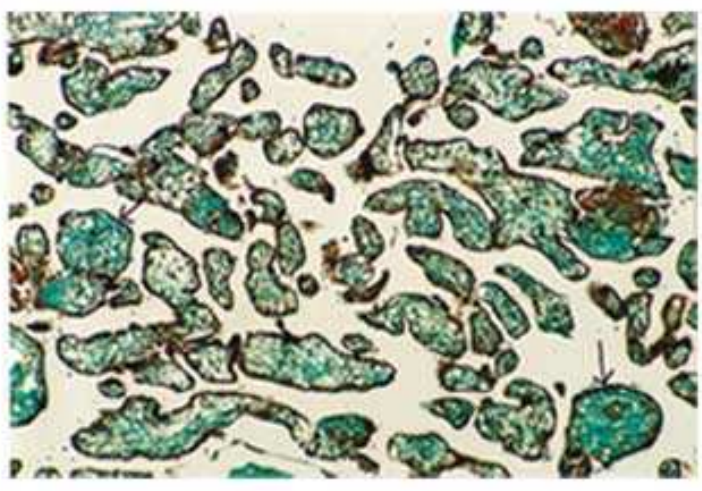

Fig 4-Villi showing Increased Stromal fibrosis (M.T.S, X10) 